\title{
Read Codes for the mental health professions: an update
}

\author{
John Wing and Susannah Rix
}

An introductory article on the Clinical Terms Project was published in the Psychiatric Bulletin last year (Wing, 1993). The Mental Health Specialty Working Group (SWG-MH) is part of a large project, extending across all medical and allied specialities, which is administered from the NHS Centre for Coding and Classification (Director, Dr James Read) of the Information Management Group of the NHS Management Executive. The work has proceeded rapidly and the SWG-MH has now submitted lists of terms for diagnoses, symptoms, signs, tests, therapies and legal procedures. These should be available for local application in Version 3 of the Read Codes in April 1994.

\section{ICD and DSM diagnoses}

Chapter F of ICD-10 (like DSM-III-R and DSM-IV) has an associated set of algorithms (the Diagnostic Criteria for Research) which, when applied to a clinical data set such as that in SCAN-PSE 10 allows a standard categorisation to be derived (WHO, 1992; Wing et al, 1994). SWG-MH has provided a two-way mapping schema between ICD-9 and ICD-10 and is now examining the algorithms for DSM-IV (which like DSM-III-R are coded to ICD-9). Read Codes for all these diagnostic systems should therefore be ready in good time for the official changeover to ICD-10 in April 1995.

\section{Clinical terms}

Most of the symptoms and signs specified in the DCR (Diagnostic Criteria for Research) for ICD-10 are included, with differential definitions, in SCAN/PSE 10; forming the base for the mental health Read Code data set. The SWG-MH has ensured that this core has been supplemented to cover the whole range of terms commonly used in the clinical record, including those for children's and for developmental disorders.

These lists have been circulated to the other 48 groups taking part in the Clinical Terms Project (CTP). Several of these are of particular importance because of a substantial overlap between specialty interests. For example, the Neuroscience, Geriatrics, Child Health, Pain, Nursing, and Speech and Language Therapy Groups are commenting on our lists and we on theirs. A Psychology Steering Group is now being set up, which will lead to a full Specialty Working Group (SWG) and we shall collaborate closely in order to promote our joint interests.

In order to limit duplication, most terms that are used by several specialties are allocated only one slot. For example, 'breathlessness' appears under Respiratory Symptoms, and 'tachycardia' under Cardiovascular Symptoms. All the SWGMH needs to do is to ensure that terms such as these, which are commonly used in clinical mental health records, do have a code somewhere in the structure. Similarly, terms such as 'hysterical deafness', which ear, nose and throat specialists might want, are inserted under our heading of Dissociative Disorders. All terms, no matter where they are classified in the Read structure, will be readily available for use in customised local mental health information systems.

\section{Procedures}

A third type of list deals with physical treatments, psychotherapies, counselling, psychological and laboratory tests, and legal procedures such as the Mental Health Act. The Read Code Drug Dictionary includes all the drugs and appliances in the British National Formulary and Drug Tariff. All known poisons and side-effects of medication will be coded. Mapping will be available to many other national and international coding systems. The new Psychology Steering Group will be amplifying our lists under some of these headings (Rix et al, 1993).

\section{The process of care}

This category includes terms like 'domiciliary visit', 'referral letter' and 'community psychiatric nurse'. A full set, together with the ability to link each one to relevant clinical concepts, is essential for the operation of any eventual health 
information system for clinical use. Preliminary work has been carried on in parallel with the main CTP but much more needs to be done.

\section{Further information on the CTP}

Susannah Rix will be glad to answer queries about the work of the SWG-MH. A useful general introductory leaflet is available from the NHS Centre for Coding and Classification, Woodgate, Loughborough, LE11 2TG (NHS-CCC, 1993).

\section{The context of CRU (College Research Unit) research}

The work on Read Codes is part of an overall CRU strategy for the development of mental health informatics to serve the purposes of clinical care, audit (Lelliott, 1993a), resource management, and casemix (Anthony et al, 1992), planning, contracting, measuring outcomes, quality monitoring, epidemiology and central returns. Part of the research programme of the CRU includes these aspects, as described in a recent paper (Lelliott, 1993b). Read Codes are basic to the rest in the sense that we need them in order to construct customised mental health information systems (Lelliott et al, 1993) of several different kinds. Further information may be obtained from the Research Unit Administrator. Please note that the CRU has moved to new offices, very close to the College: 11 Grosvenor Crescent,
SW 1X 7EE. Telephone and fax numbers remain the same.

\section{References}

ANThoNy, P., ElPhick, M. \& Lelliott, P. (1992) Casemix in psychiatry. Psychiatric Bulletin. 17, 8-9.

LELLIOTT, P. (1993a) Making medical audit effective. Psychiatry Spectalty Supplement. Joint Centre for Education in Medicine/Royal College of Psychiatrists Research Unit. - (1993b) An update on the activities of the College Research Unit. Psychiatric Bulletin, 18, 58-61.

- Flannigan, C. \& Shanks, S. (1993) A Review of seven Mental Health Information Systems. A functional perspective. Research Unit Publication No. 1. London: Royal College of Psychiatrists.

NHS CENTRE FOR CODING AND Classification (1993) Read Codes and the Terms Projects. A brlef guide. London Department of Health.

Rix. S., Christie. M. \& WING. J.K. (1993) The role of the Mental Health SWG in the development of the Read Codes. Clinical Psychology Forum, December, 34-36.

WING, J.K. (1993) Read Codes for the mental health professions. The Clinical Terms Project. Psychiatric Bulletin. 17. 195-196.

- SARTORIUS, M. \& USTON. T.B. (1994) Diagnosis and Clinical Measurement in Psychiatry. A reference manual for the SCAN system. Cambridge: Cambridge University Press. (In press).

WORLD HEALTH ORganization (1992) ICD-10 Mental and Behavioural Disorders. Diagnostic criterla for research. Geneva: WHO.

John Wing, Director; and Susannah Rix, Research Worker, Royal College of Psychiatrists Research Unit, 11 Grosuenor Crescent, London SWIX 7EE 